CLINICAL STUDY

\title{
Desmopressin test during petrosal sinus sampling: a valuable tool to discriminate pituitary or ectopic ACTH-dependent Cushing's syndrome
}

\author{
F Castinetti, I Morange, H Dufour ${ }^{1}$, P Jaquet, B Conte-Devolx, N Girard ${ }^{2}$ and T Brue \\ Federation of Endocrinology, Diabetes, Metabolic Diseases and Nutrition, ${ }^{1}$ Department of Neurosurgery and ${ }^{2}$ Department of Neuroradiology, Hôpital de la \\ Timone, Centre Hospitalier Universitaire de Marseille and Faculté de Médecine, Université de la Méditerranée 13385 Marseille, France \\ (Correspondence should be addressed to T Brue at Department of Endocrinology, Hôpital de la Timone, 264 rue St Pierre, cedex 5, 13385 Marseille, France; \\ Email: thierry.brue@mail.ap-hm.fr)
}

\begin{abstract}
Corticotropin-releasing hormone ( $\mathrm{CRH})$-stimulated petrosal sinus sampling is currently the gold standard method for the differential diagnosis between pituitary and ectopic ACTH-dependent Cushing's syndrome. Our objective was to determine sensitivity and specificity of desmopressin test during petrosal sinus sampling.

Patients and methods: Forty-three patients had petrosal sinus sampling because of the lack of visible adenoma on magnetic resonance imaging (MRI) and/or because of discordant cortisol response to high-dose dexamethasone suppression test. ACTH sampling was performed in an antecubital vein, right and left petrosal sinuses, then at each location 5 and 10 min after injection of desmopressin. Diagnosis was based on the ACTH ratio between petrosal sinus and humeral vein ACTH after desmopressin test. Diagnosis was confirmed after surgery. A receiver operating characteristics curve was used to determine optimal sensitivity and specificity.

Results: Thirty-six patients had Cushing's disease (CD) and seven had ectopic ACTH secretion. A ratio $>2$ after desmopressin was found in 35 of the 36 cases of $C D$ (sensitivity: 95\%). A ratio $\leq 2$ was found in the seven patients with ectopic ACTH secretion (specificity: 100\%). Sinus sampling was ineffective in determining the left or right localization of the adenoma (sensitivity $=50 \%$ ). No major adverse effects were observed during or after the procedure.

Conclusion: Desmopressin test during petrosal sinus sampling is a safe and effective diagnostic procedure in ACTH-dependent Cushing's syndrome. It thus represents a valuable alternative to CRH.

European Journal of Endocrinology 157 271-277
\end{abstract}

\section{Introduction}

Adrenocorticotropin (ACTH)-dependent Cushing's syndrome may be caused by a pituitary corticotrope adenoma (Cushing's disease (CD), $80-85 \%$ of cases), by an extrapituitary tumor (ectopic ACTH secretion (EAS)), or very rarely by a corticotropin-releasing hormone (CRH)-secreting tumor (ectopic CRH syndrome). When diagnosed, because of signs and symptoms of chronic endogenous glucocorticoid excess, most corticotrope adenomas are microadenomas $(<10 \mathrm{~mm}$ in largest diameter) $(1,2)$. Distinguishing between $\mathrm{CD}$ and EAS can be difficult because clinical and biological features are often similar, the source of ACTH secretion is not always readily identified by pituitary magnetic resonance (MR) imaging in case of small microadenomas, or by current imaging techniques in case of ectopic source. Moreover, classical diagnostic tests are sometimes discordant: for instance, partial suppression of cortisol after high-dose dexamethasone test (3-5).
Simultaneous bilateral inferior petrosal sinus catheterization and sampling, with CRH stimulation, is currently the gold standard to differentiate between $\mathrm{CD}$ and EAS. This procedure has been initially reported to have $100 \%$ sensitivity and specificity (6). However, since the first published series in the early 1990s, other reports have shown the technique to have much less discriminatory power (7-12).

Among the various agents that may interfere with the complex regulation of the hypothalamus-pituitaryadrenal axis, vasopressin is one of the most powerful stimuli of ACTH secretion via its binding to pituitary vasopressin type 3 (V3) receptors $(13,14)$. Desmopressin, a vasopressin agonist, could indeed theoretically stimulate adrenocorticotropin secretion by a pituitary tumor that expresses V2 and V3 receptors. However, few researchers observed the expression of $\mathrm{V} 2$ and $\mathrm{V} 3$ receptors in some ectopic tumors producing ACTH $(15,16)$.

Since 1995, we substituted CRH by desmopressin in bilateral inferior petrosal sinus sampling (IPSS). 
The aim of our study was to evaluate this procedure as a diagnostic tool in the diagnosis of $\mathrm{CD}$ and EAS. We assessed the efficacy of this technique in 43 patients and defined a cut-off value for highest sensitivity and specificity. In this setting, the desmopressin test during the IPSS appeared as a safe and consistent procedure.

\section{Patients and methods}

\section{Patients}

Between 1995 and 2005, bilateral IPSS was performed in 36 patients because of clinical and biological evidence of ACTH-dependent Cushing's syndrome without MR image of the adenoma $(80 \%)$ or because of discordant cortisol response to high-dose dexamethasone suppression test $(20 \%)$; in seven of them because of lack of MR image and of cortisol suppression. We retrospectively evaluated these cases to determine (1) whether sampling was useful in differentiating CD and EAS and (2) in case of CD, whether it could be helpful for the neurosurgeon in determining the left or right lateralization of the adenoma.

The diagnosis of $\mathrm{CD}(n=36)$ was confirmed by histological examination of a surgical specimen in 28 patients, or on the basis of long-term remission after surgical treatment despite the lack of available tumor fragments for histological examination (five patients), or in case of remission after pituitary radiosurgery (three patients). The diagnosis of ACTH ectopic secretion was proven by histological examination of the specimen in seven cases (four patients with bronchial carcinoid, one with pancreatic carcinoma, one with thymic carcinoid and one with medullar carcinoma of the thyroid). Diagnoses were established in 43 patients with hypercortisolism who underwent successful sampling, i.e. 36 patients with $\mathrm{CD}$ and 7 with EAS.

The predictive value of simultaneous bilateral sampling of the inferior petrosal sinuses for determining the lateralization of the microadenoma was assessed in the 28 patients in whom microadenoma was identified intraoperatively as being either on one side or at the midline of the pituitary.

\section{Catheterization procedure}

Catheterization of both inferior petrosal sinuses was performed through a percutaneous bilateral femoral vein approach. After a catheter was advanced into a petrosal sinus, a small amount of contrast material was injected to verify the location of the catheter tip. Blood was slowly withdrawn from both catheters simultaneously and from a peripheral vein for adrenocorticotropin measurement. Desmopressin in a dose of $10 \mu \mathrm{g}$ was then infused into a peripheral vein, and samples were simultaneously obtained from both inferior petrosal sinuses and peripheral vein 5 and $10 \mathrm{~min}$ after the administration of desmopressin. No anticoagulation was used during the procedure.

For the differential diagnosis between CD and EAS, the ACTH values were used to calculate the ratio of ACTH between the right or left inferior petrosal sinus and the concentration in the peripheral blood (IPS:P ratio) and the maximal ratio (right or left) was identified. Sampling giving the highest value of ACTH (5 or 10 min after the injection of desmopressin) was used to determine the ratio. The ratio corresponding to the highest sensitivity and specificity was determined using a receiver operator characteristics (ROC) curve.

To correlate the results of sampling with the site of the microadenoma in the pituitary gland, the location of the microadenoma as identified at surgery was assigned to the right or left side of the pituitary. The concurrent ACTH concentration in the inferior petrosal sinuses was used to calculate a ratio between the concentration of the two sides (lateralization gradient, L ratio).

\section{Statistical analysis}

Data were analyzed using non-parametric tests, using Microsoft Office Excel and SPSS (version 13.0 for Windows; SPSS Inc., Chicago, IL, USA). The Wilcoxon test was used for the analysis of the variations of plasma ACTH before and after desmopressin stimulation, $P$ was considered significant when $<0.05$. Sensitivity and specificity were derived from the ROC curve.

\section{Results}

Sampling was successfully performed in all of our patients $(n=43)$. Bilateral catheterization was possible in all but one, in whom positioning of catheter in the left sinus was impossible due to congenital malformation (only one jugular vein was present). Indeed, each inferior petrosal sinus and humeral vein were simultaneously sampled in 42 patients. Individual data with the results of high-dose dexamethasone suppression test, MRI, petrosal sinus sampling, and surgically proven diagnosis are given in Table 1. Results between high-dose dexamethasone suppression test and IPSS were discordant in 20\% of cases. Mean and extreme values of ACTH sampling before and after stimulation in each etiologic group of patients (CD or EAS) are given in Table 2.

\section{IPS:P ratio in basal sampling}

The ratio value corresponding to the highest sensitivity and specificity for differential diagnosis between CD and EAS was defined with a ROC curve: the defined optimal cut-off value of 2 was used for statistical analysis (Fig. 1). Out of the 36 patients with CD, 32 had an ACTH IPS:P ratio $>2$ (sensitivity $86 \%$ ). Out of the seven patients with EAS, six had a maximal basal IPS:P ratio 
Table 1 Individual data in 43 patients, with the results of high-dose dexamethasone suppression test, magnetic resonance (MR) imaging (either presence or lack of clearly visible image of pituitary adenoma), central-to-periphery adrenocorticotropin (ACTH) gradient in favor of Cushing's disease, and diagnosis as confirmed after surgery.

\begin{tabular}{|c|c|c|c|c|c|}
\hline Patient number & Sex/age & $\begin{array}{l}\text { HDDT cortisol } \\
\text { suppression }\end{array}$ & Evident MR image & IPSS gradient $>2$ & Surgical diagnosis \\
\hline 1 & M/31 & No & Yes & Yes & CD \\
\hline 2 & $\mathrm{~F} / 60$ & No & Yes & Yes & CD \\
\hline 3 & $\mathrm{~F} / 14$ & No & Yes & Yes & CD \\
\hline 4 & $\mathrm{~F} / 73$ & No & Yes & Yes & CD \\
\hline 5 & $F / 53$ & No & Yes & Yes & CD \\
\hline 6 & $\mathrm{~F} / 42$ & No & Yes & Yes & $C D$ \\
\hline 7 & M/32 & No & Yes & Yes & CD \\
\hline 8 & $M / 50$ & Yes & No & No & $C D$ \\
\hline 9 & $\mathrm{~F} / 20$ & Yes & No & Yes & $C D$ \\
\hline 10 & $\mathrm{~F} / 56$ & Yes & No & Yes & CD \\
\hline 11 & $\mathrm{~F} / 42$ & Yes & No & Yes & CD \\
\hline 12 & $\mathrm{~F} / 50$ & Yes & No & Yes & $C D$ \\
\hline 13 & $\mathrm{~F} / 8$ & Yes & No & Yes & CD \\
\hline 14 & $F / 48$ & Yes & No & Yes & CD \\
\hline 15 & $\mathrm{~F} / 31$ & Yes & No & Yes & CD \\
\hline 16 & $\mathrm{~F} / 50$ & Yes & No & Yes & $C D$ \\
\hline 17 & $\mathrm{~F} / 72$ & Yes & No & Yes & CD \\
\hline 18 & $\mathrm{~F} / 46$ & Yes & No & Yes & CD \\
\hline 19 & $\mathrm{~F} / 17$ & Yes & No & Yes & CD \\
\hline 20 & $\mathrm{~F} / 50$ & Yes & No & Yes & $C D$ \\
\hline 21 & $\mathrm{~F} / 53$ & Yes & No & Yes & CD \\
\hline 22 & $\mathrm{~F} / 46$ & Yes & No & Yes & CD \\
\hline 23 & $\mathrm{~F} / 55$ & Yes & No & Yes & CD \\
\hline 24 & $\mathrm{M} / 36$ & Yes & No & Yes & CD \\
\hline 25 & $\mathrm{~F} / 58$ & Yes & No & Yes & CD \\
\hline 26 & $\mathrm{~F} / 26$ & Yes & No & Yes & CD \\
\hline 27 & $\mathrm{M} / 53$ & Yes & No & Yes & CD \\
\hline 28 & $F / 28$ & Yes & No & Yes & CD \\
\hline 29 & $\mathrm{~F} / 42$ & Yes & No & Yes & CD \\
\hline 30 & $\mathrm{M} / 45$ & Yes & No & Yes & CD \\
\hline 31 & $F / 32$ & Yes & No & Yes & CD \\
\hline 32 & M/38 & Yes & No & Yes & CD \\
\hline 33 & $\mathrm{~F} / 39$ & yes & No & Yes & $C D$ \\
\hline 34 & $\mathrm{~F} / 45$ & Yes & No & Yes & CD \\
\hline 35 & $\mathrm{~F} / 24$ & Yes & No & Yes & $C D$ \\
\hline 36 & $F / 24$ & Yes & No & Yes & CD \\
\hline 37 & $\mathrm{M} / 61$ & No & No & No & EAS \\
\hline 38 & $\mathrm{~F} / 50$ & No & No & No & EAS \\
\hline 39 & $F / 63$ & No & No & No & EAS \\
\hline 40 & $\mathrm{M} / 58$ & No & No & No & EAS \\
\hline 41 & $\mathrm{~F} / 69$ & No & No & No & EAS \\
\hline 42 & $\mathrm{~F} / 39$ & No & No & No & EAS \\
\hline 43 & $\mathrm{~F} / 59$ & No & No & No & EAS \\
\hline
\end{tabular}

F, female; M, male; HDDT, high-dose dexamethasone test; CD, Cushing's disease; and EAS, ectopic adrenocorticotropin secretion. As detailed in text, only one patient (\#8, bold) with CD had an IPSS gradient $<2$.

of $<2$. Thus, the diagnostic specificity of a basal ratio $>2$ was $85 \%$.

\section{IPS:P ratio after desmopressin stimulation}

Out of the 36 patients with CD, 32 had an ACTH ratio $>2$ (sensitivity 97\%) (Fig. 2). The only case where we observed falsely negative results was a male aged 50 , who presented typical clinical hypercortisolism with normal pituitary MR imaging; highest basal ratio was 1.09 , increasing to 1.16 after desmopressin; explorative transsphenoidal surgery, finally performed because of the lack of consistent findings supporting an ectopic secretion, found a microadenoma of the left side of the pituitary, confirmed by histological examination, measuring $1 \mathrm{~mm}$ at its largest diameter. All of the seven patients with EAS had a maximal basal IPS:P ratio of $<2.0$ (specificity $100 \%$ ) (Table 2 ).

Ratio increased from 11.6 to 27.8 after desmopressin for patients with $\mathrm{CD}(P<0.05)$, and remained unchanged $(1.7$ vs $1.33, \quad P<0.05)$ in patients with EAS.

\section{Lateralization of the microadenoma in CD}

Pituitary adenoma was surgically confirmed in 28 cases. Fifteen patients $(54 \%)$ had an intersinus gradient 
Table 2 Values of adrenocorticotropin (ACTH; pg/ml) before and after desmopressin stimulation in periphery (humeral vein) and in each petrosal sinus.

\begin{tabular}{lcr}
\hline & Cushing's disease $(n=36)$ & Ectopic ACTH secretion $(n=7)$ \\
\hline Basal ACTH & & $97.25(12-205)$ \\
Humeral & $55(5-255)$ & $112.5(17-238)$ \\
Right IPS & $436(25-2120)^{\star}$ & $118.25(40-240)$ \\
Left IPS & $188(5-800)$ & $146(16-195)$ \\
Maximal post-stimulation ACTH & & $166(18-205)$ \\
Humeral & $216(22-1840)$ & $158(32-221)$ \\
Right IPS & $3058(63-38900)^{\star}$ & $1.7(1.09-3.33)$ \\
Left IPS & $2118(24-26600)^{*}$ & $1.33(1.13-1.90)$ \\
Basal IPS:P ratio & $11.6(1.1-64.8)^{\star}$ & \\
Maximal post-stimulation IPS:P ratio & $27.8(1.16-474.4)^{\star}$ & \\
\hline
\end{tabular}

Values of the ratio between petrosal sinus and humeral ACTH sampling before and after desmopressin stimulation. *Denotes a significant difference between Cushing's disease and ectopic adrenocorticotropin secretion $(P<0.05)$. IPS, inferior petrosal sinus; $P$, periphery (humeral vein).

corresponding to the left or right side of the adenoma. This result was not modified after injection of desmopressin. The wide range of results in the lateralization ratio (L ratio; ranging from 1 to 35 when wrong side was indicated, and 1.1 to 14 when correct side was indicated), even after stimulation, made it impossible to determine a correct maximal value of $\mathrm{L}$ ratio that would be indicative of the exact lateralization.

\section{Complications}

In seven patients, catheterization led to hematomas at the site of venous puncture. No major complication was observed.

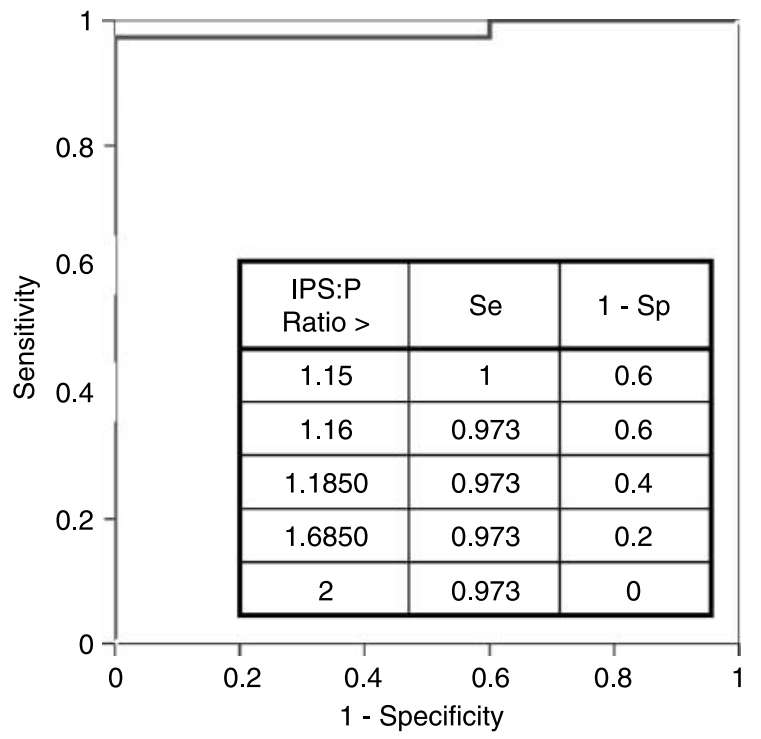

Figure 1 Receiver operator characteristics curve. Value of the ACTH ratio between intrapetrosal and humeral sampling after desmopressin stimulation. Insert: sensitivity and specificity according to the ratio between petrosal sinus and humeral ACTH sampling after desmopressin stimulation. Highest sensitivity and specificity were obtained with a ratio cut-off value of 2 .

\section{Discussion}

Both low- and high-dose dexamethasone suppression tests have been widely used for the differential diagnosis between EAS and CD. However, even combined with $\mathrm{CRH}$ stimulation test, these tests do not give optimal

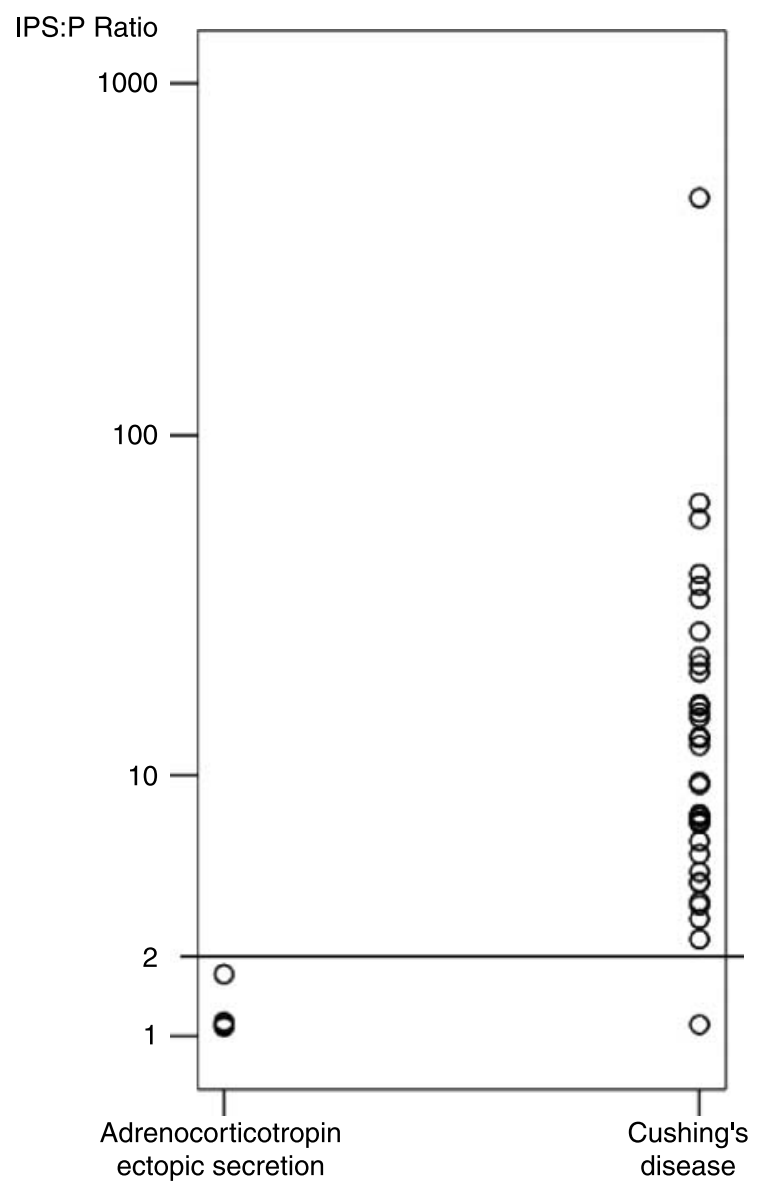

Figure 2 Ratio between intrapetrosal and periphery ACTH sampling (IPS:P ratio) in 43 patients, with Cushing's disease $(n=36)$ or ectopic adrenocorticotropin secretion $(n=7)$. Ratio after desmopressin stimulation is represented on a logarithmic scale. 
Table 3 Performance (specificity and sensitivity) of the desmopressin test during inferior petrosal sinus sampling (IPSS) alone or coupled with corticotropin-releasing hormone $(\mathrm{CRH})$, in the present study and published reports.

\begin{tabular}{llcccc}
\hline Author & Procedure & Patients with CD & Patients with EAS & Sensitivity & Specificity \\
\hline Our study & Desmopressin & 36 & 7 & 0.97 & 1 \\
Machado et al. (26) & Desmopressin & 50 & 5 & 0.92 & 1 \\
Tsagarakis et al. (33) & CRH and desmopressin & 47 & 7 & 0.97 & 1 \\
\hline
\end{tabular}

Number of patients $(n)$ described with Cushing's disease (CD) or ectopic ACTH secretion (EAS).

sensitivity and specificity (2). The use of the inferior petrosal sinus catheterization procedure was first described by Corrigan in 1977 in the differential diagnosis between both conditions (17). This diagnostic procedure was improved by the addition of CRH stimulation described by Landolt et al. in 1986 (18).

The first large-scale study published by Oldfield in 1991 on CRH-stimulated bilateral IPSS reported an accuracy of $100 \%$, but as many as $15 \%$ of the patients had an uncertain diagnosis, making it difficult to assess actual performance of the procedure (6). Several studies were then published with the use of $\mathrm{CRH}$, showing a wide range of accuracy rates varying from 80 to $100 \%$ (19-24). Our study, based on desmopressin-stimulated IPSS, found comparable results with a sensitivity of $96 \%$ and a specificity of $100 \%$ with a similar cut-off value of 2 determined by ROC curve analysis.

Two series have been published previously with the use of desmopressin-stimulated intrapetrosal sinus sampling. The first $(n=26$ patients with $\mathrm{CD}$ and 4 with EAS) tried to compare the use of $\mathrm{CRH}$ with desmopressin during bilateral petrosal sinus sampling the procedure showed an accuracy of about $90 \%$ of cases in differentiating $\mathrm{CD}$ and ectopic ACTH secretion (25). The second ( $n=56$ patients, 5 EAS) found a sensitivity of $92 \%$ and a specificity of $100 \%$ (26). In both studies, stimulation by desmopressin allowed an increase in sensitivity from 80 to more than $90 \%$. The central-to-periphery ratio cut-off value of 2 was determined in our series by ROC curve to differentiate CD (ratio $>2$ ) and EAS (ratio $\leqslant 2$ ). The same value was used in the largest series based on desmopressinstimulated petrosal sinus sampling (26). A central to periphery ratio value of 3 was classically used in the series using CRH stimulation (6).

The rationale for the use of desmopressin, a longacting synthetic vasopressin analog, in the diagnosis of $\mathrm{CD}$, is based on the overexpression of $\mathrm{V} 2$ desmopressin receptors in corticotrope adenoma cells (27). The injection of desmopressin stimulates the secretion of ACTH in case of CD, and theoretically not in EAS (28). However, a few studies described occasional expression of desmopressin receptors in ectopic adrenocorticotropin secretion $(15,16,29,30)$. Our study found a clear difference between both conditions after stimulation by desmopressin, with a significantly increased gradient in case of $\mathrm{CD}$ and not in EAS.
As expected, despite the value of desmopressin testing during IPSS as a diagnostic tool to differentiate CD and EAS (31), this procedure in no way allows the determination of the side of the adenoma. We found low sensitivity, equal to $50 \%$ of cases, in keeping with previously published series $(10,25,26)$. This result can probably be explained by a pre-existing communication between the cavernous sinuses or by a controlateral drainage dominance of one side (32). Prediction of the lateralization of the adenoma with petrosal sinus sampling can be biased by the catheter position or abnormal venous drainage, and this point cannot be modified by the type of secretagog used, desmopressin or CRH.

As very few data are published for the use of desmopressin during petrosal sinus sampling, our study confirms the role of this procedure in the differential diagnosis of ACTH-dependent Cushing's syndrome. Indeed, few patients presenting EAS had previously been evaluated with this procedure (Table 3 ). Adding the seven patients reported in this series, desmopressin stimulation during petrosal sinus sampling currently presents with a specificity of $100 \%$, and a sensitivity exceeding 90\%, comparing well with the results obtained with CRH stimulation. Comparison with recently described combined CRH and desmopressin stimulation petrosal sinus sampling is difficult as only few studies are published on these procedures (33). However, as shown in Table 3, combining both secretagogs may improve the sensitivity of the procedure. Other studies will be necessary to better evaluate the accuracy of each procedure, particularly concerning ectopic ACTH secretion, as only few cases have been evaluated since then.

The wide availability of desmopressin compared with $\mathrm{CRH}$ and the high sensitivity and specificity of desmopressin-stimulated petrosal sinus sampling make it a valuable alternative method in the differential diagnosis of ACTH-dependent Cushing's syndrome.

\section{Acknowledgements}

The authors wish to express their thanks to the staff of the Endocrinology and Neuroradiology departments, to the patients and their referring physicians for their involvement in this study. 


\section{References}

1 Plotz CM, Knowlton AI \& Ragan C. The natural history of Cushing's syndrome. American Journal of Medicine 195213 597-614.

2 Arnaldi G, Angeli A, Atkinson AB, Bertagna X, Cavagnini F, Chrousos GP, Fava GA, Findling JW, Gaillard RC, Grossman AB, Kola B, Lacroix A, Mancini T, Mantero F, Newell-Price J, Nieman LK, Sonino N, Vance ML, Giustina A \& Boscaro M. Diagnosis and complications of Cushing's syndrome: a consensus statement. Journal of Clinical Endocrinology and Metabolism 2003 88 5593-5602.

3 Howlett TA, Drury PL, Perry L, Doniach I, Rees LH \& Besser GM. Diagnosis and management of ACTH-dependent Cushing's syndrome: comparison of the features in ectopic and pituitary ACTH production. Clinical Endocrinology 198624 699-713.

4 Orth DN. Cushing's syndrome. New England Journal of Medicine 1995332 791-803.

5 Trainer PJ \& Grossman A. The diagnosis and differential diagnosis of Cushing's syndrome. Clinical Endocrinology 199134 317-330.

6 Oldfield EH, Doppman JL, Nieman LK, Chrousos GP, Miller DL, Katz DA, Cutler GB Jr \& Loriaux DL. Petrosal sinus sampling with and without corticotropin-releasing hormone for the differential diagnosis of Cushing's syndrome. New England Journal of Medicine 1991325 897-905.

7 Kaye TB \& Crapo L. The Cushing syndrome: an update on diagnostic tests. Annals of Internal Medicine 1990112 434-444.

8 Findling JW, Kehoe ME, Shaker JL \& Raff H. Routine inferior petrosal sinus sampling in the differential diagnosis of adrenocorticotropin (ACTH)-dependent Cushing's syndrome: early recognition of the occult ectopic ACTH syndrome. Journal of Clinical Endocrinology and Metabolism 199173 408-413.

9 Landolt AM, Schubiger O, Maurer R \& Girard J. The value of inferior petrosal sinus sampling in diagnosis and treatment of Cushing's disease. Clinical Endocrinology 199440 485-492.

10 Batista D, Gennari M, Riar J, Chang R, Keil MF, Oldfield EH \& Stratakis CA. An assessment of petrosal sinus sampling for localization of pituitary microadenomas in children with Cushing disease. Journal of Clinical Endocrinology and Metabolism 200691 221-224.

11 Testa RM, Albiger N, Occhi G, Sanguin F, Scanarini M, Berlucchi S, Gardiman MP, Carollo C, Mantero F \& Scaroni C. The usefulness of combined biochemical tests in the diagnosis of Cushing's disease with negative pituitary magnetic resonance imaging. European Journal of Endocrinology 2007156 241-248.

12 Fujimura M, Ikeda H, Takahashi A, Ezura M, Yoshimoto T \& Tominaga T. Diagnostic value of super-selective bilateral cavernous sinus sampling with hypothalamic stimulating hormone loading in patients with ACTH-producing pituitary adenoma. Neurological Research 200527 11-15.

13 de Keyzer Y, Rene P, Beldjord C, Lenne F \& Bertagna X. Overexpression of vasopressin (V3) and corticotrophin-releasing hormone receptor genes in corticotroph tumours. Clinical Endocrinology $199849475-482$.

14 Antoni FA. Novel ligand specificity of pituitary vasopressin receptors in the rat. Neuroendocrinology 198439 186-188.

15 Chabot V, de Keyzer Y, Gebhard S, Uske A, Bischof-Delaloye A, Rey F, Dusmet M \& Gomez F. Ectopic ACTH Cushing's syndrome: V3 vasopressin receptor but not CRH receptor gene expression in a pulmonary carcinoid tumor. Hormone Research 199850 226-231.

16 Tsagarakis S, Tsigos C, Vasiliou V, Tsiotra P, Kaskarelis J, Sotiropoulou C, Raptis SA \& Thalassinos N. The desmopressin and combined CRH-desmopressin tests in the differential diagnosis of ACTH-dependent Cushing's syndrome: constraints imposed by the expression of V2 vasopressin receptors in tumors with ectopic ACTH secretion. Journal of Clinical Endocrinology and Metabolism 200287 1646-1653.

17 Corrigan DF, Schaaf M, Whaley RA, Czerwinski CL \& Earll JM. Selective venous sampling to differentiate ectopic ACTH secretion from pituitary Cushing's syndrome. New England Journal of Medicine 1977296 861-862.
18 Landolt AM, Valavanis A, Girard J \& Eberle AN. Corticotrophinreleasing factor-test used with bilateral, simultaneous inferior petrosal sinus blood-sampling for the diagnosis of pituitarydependent Cushing's disease. Clinical Endocrinology 198625 687-696.

19 Newell-Price J, Trainer P, Besser M \& Grossman A. The diagnosis and differential diagnosis of Cushing's syndrome and pseudoCushing's states. Endocrine Reviews 199819 647-672.

20 Invitti C, Pecori Giraldi F, de Martin M \& Cavagnini F. Diagnosis and management of Cushing's syndrome: results of an Italian multicentre study. Study Group of the Italian Society of Endocrinology on the Pathophysiology of the hypothalamicpituitary-adrenal axis. Journal of Clinical Endocrinology and Metabolism $1999 \mathbf{8 4}$ 440-448.

21 Kaltsas GA, Giannulis MG, Newell-Price JD, Dacie JE, Thakkar C, Afshar F, Monson JP, Grossman AB, Besser GM \& Trainer PJ. A critical analysis of the value of simultaneous inferior petrosal sinus sampling in Cushing's disease and the occult ectopic adrenocorticotropin syndrome. Journal of Clinical Endocrinology and Metabolism $1999 \mathbf{8 4} 487-492$.

22 Colao A, Faggiano A, Pivonello R, Pecori Giraldi F, Cavagnini F \& Lombardi G. Inferior petrosal sinus sampling in the differential diagnosis of Cushing's syndrome: results of an Italian multicenter study. European Journal of Endocrinology 2001144 499-507.

23 Bonelli FS, Huston J, III, Carpenter PC, Erickson D, Young WF $\mathrm{Jr} \&$ Meyer FB. Adrenocorticotropic hormone-dependent Cushing's syndrome: sensitivity and specificity of inferior petrosal sinus sampling. American Journal of Neuroradiology 200021 690-696.

24 Ilias I, Torpy DJ, Pacak K, Mullen N, Wesley RA \& Nieman LK. Cushing's syndrome due to ectopic corticotropin secretion: twenty years' experience at the National Institutes of Health. Journal of Clinical Endocrinology and Metabolism 200590 4955-4962.

25 Tsagarakis S, Kaskarelis IS, Kokkoris P, Malagari C \& Thalassinos N. The application of a combined stimulation with $\mathrm{CRH}$ and desmopressin during bilateral inferior petrosal sinus sampling in patients with Cushing's syndrome. Clinical Endocrinology $2000 \mathbf{5 2} 355-361$.

26 Machado MC, de Sa SV, Domenice S, Fragoso MC, Puglia P Jr, Pereira MA, de Mendonca BB \& Salgado LR. The role of desmopressin in bilateral and simultaneous inferior petrosal sinus sampling for differential diagnosis of ACTH-dependent Cushing's syndrome. Clinical Endocrinology 200766 136-142.

27 Dahia PL, Ahmed-Shuaib A, Jacobs RA, Chew SL, Honegger J, Fahlbusch R, Besser GM \& Grossman AB. Vasopressin receptor expression and mutation analysis in corticotropin-secreting tumors. Journal of Clinical Endocrinology and Metabolism $1996 \mathbf{8 1}$ 1768-1771.

28 Malerbi DA, Mendonca BB, Liberman B, Toledo SP, Corradini MC, Cunha-Neto MB, Fragoso MC \& Wajchenberg BL. The desmopressin stimulation test in the differential diagnosis of Cushing's syndrome. Clinical Endocrinology 199338 463-472.

29 Moro M, Putignano P, Losa M, Invitti C, Maraschini C \& Cavagnini F. The desmopressin test in the differential diagnosis between Cushing's disease and pseudo-Cushing states. Journal of Clinical Endocrinology and Metabolism 200085 3569-3574.

30 Terzolo M, Reimondo G, Ali A, Borretta G, Cesario F, Pia A, Paccotti P \& Angeli A. The limited value of the desmopressin test in the diagnostic approach to Cushing's syndrome. Clinical Endocrinology $2001 \mathbf{5 4} 609-616$.

31 Wiggam MI, Heaney AP, McIlrath EM, McCance DR, Sheridan B, Hadden DR \& Atkinson AB. Bilateral inferior petrosal sinus sampling in the differential diagnosis of adrenocorticotropindependent Cushing's syndrome: a comparison with other diagnostic tests. Journal of Clinical Endocrinology and Metabolism 200085 1525-1532.

32 Lefournier V, Martinie M, Vasdev A, Bessou P, Passagia JG, LabatMoleur F, Sturm N, Bosson JL, Bachelot I \& Chabre O. Accuracy of bilateral inferior petrosal or cavernous sinuses sampling in predicting the lateralization of Cushing's disease pituitary 
microadenoma: influence of catheter position and anatomy of venous drainage. Journal of Clinical Endocrinology and Metabolism 200388 196-203.

33 Tsagarakis S, Vassiliadi D, Kaskarelis IS, Komninos J, Souvatzoglou E \& Thalassinos N. The application of the combined Crh Plus desmopressin stimulation during petrosal sinus sampling is both sensitive and specific in differentiating patients with
Cushing's disease from patients with the Occult Ectopic Acth syndrome. Journal of Clinical Endocrinology and Metabolism 2007 92 2080-2086.

Received 30 March 2007

Accepted 30 May 2007 